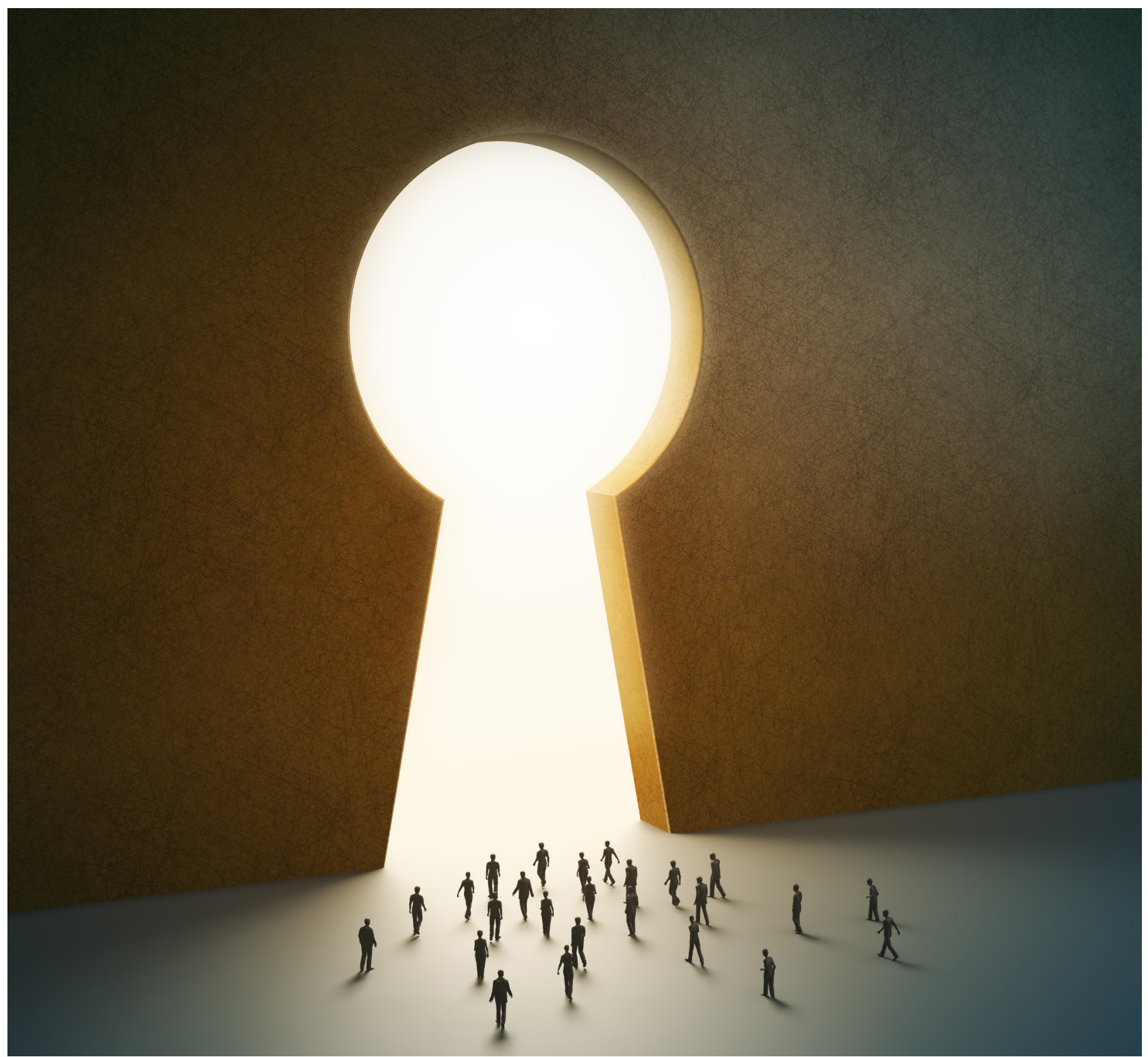

\title{
NEGÓCIOS COMO DESTINO
}

A TENDÊNCIA É FAZER COM QUE O CLIENTE ESCOLHA SUA EMPRESA COMO FAZ COM UM ROTEIRO TURÍSTICO, COM A EXPECTATIVA DE TER UMA EXPERIÊNCIA DE SERVIÇO ÚNICA, INTENSA E MEMORÁVEL. 


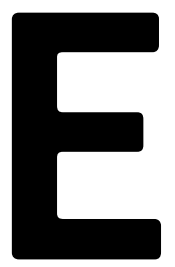

m tempos de produtos e serviços facilmente acessíveis e copiáveis, a experiência oferecida ao cliente tornou-se uma fonte de vantagem competitiva. Muito se fala sobre esse tema, mas entregar, de fato, uma sensação única, memorável e sustentável aos consumidores exige mudanças estruturais que poucas organizações têm conseguido alcançar. Em pesquisa com 1.269 líderes de nove países realizada no ano passado, a Forrester Consulting constatou que mais de $60 \%$ deles dizem que suas organizações promovem experiências ao cliente, mas que apenas $31 \%$ trabalham em negócios verdadeiramente guiados pela experiência.

A maioria das empresas trabalha com prestação de serviços comum, que oferece interação pontual, limitada e estática com o consumidor - como a reserva de uma acomodação para a próxima viagem. Expandir essa experiência faz com que as pessoas queiram revivê-la e recomendá-la - como fez a Airbnb ao criar sua plataforma de experiências, em que moradores locais proporcionam a viajantes incursões singulares ao, por exemplo, compartilharem seus roteiros

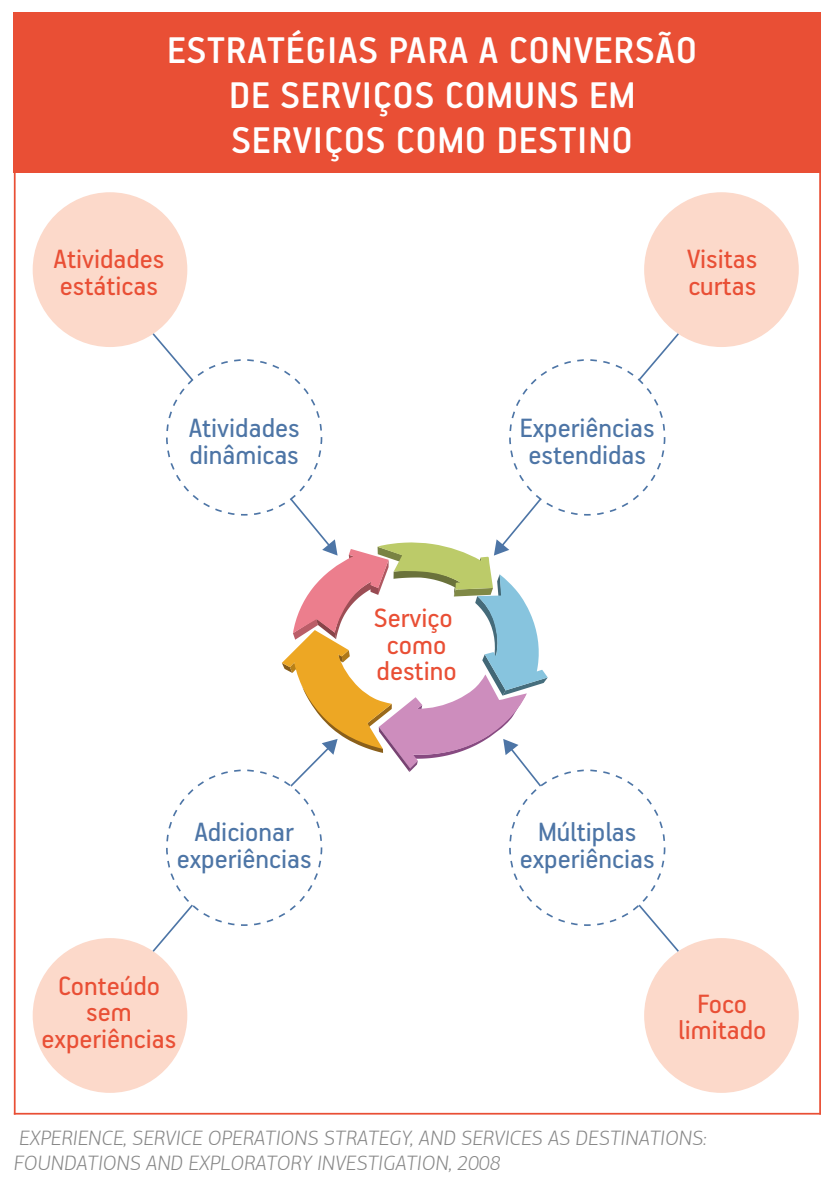

secretos pela cidade ou os receberem para jantar em suas próprias casas.

Esse é um tipo de serviço a ser experimentado intensamente e que causa sensações por um longo período, isto é, o serviço como um "destino". A metáfora tem ligação com os serviços de turismo, nos quais você escolhe um destino e tem a intenção de aproveitá-lo ao máximo.

Neste artigo, discutimos como as empresas podem alcançar o objetivo de promover o serviço como um "destino" e o que devem mudar em suas operações para oferecer uma experiência ampliada.

\section{ESTRATÉGIAS PARA SERVIÇOS COMO DESTINO}

As empresas interessadas em transformar seu serviço em um destino possuem quatro diferentes estratégias ao seu dispor:

- Agregar atividades dinâmicas. Em alguns serviços, o cliente possui pouca influência em como o serviço é prestado. Um exemplo são os restaurantes a la carte. $\mathrm{O}$ cliente entra, escolhe um prato, come, paga a conta $\mathrm{e}$ vai embora. A franquia de culinária japonesa Benihana conseguiu dinamizar o processo de produção dos pratos. A preparação passou a ser feita na frente dos clientes, por chefs treinados para interagir com eles. Os clientes podem fazer pedidos e participar dos truques realizados. Pense no seu negócio: será que mostrar o que não é visível aos clientes é uma alternativa? Há alguma forma de aumentar a participação deles em atividades-chave do seu serviço? Ter um modelo de negócios baseado na interação com os consumidores pode demandar mudanças significativas. Funcionários da linha de frente devem ser qualificados e preparados para atuar com o público, e é preciso deixar claro aos clientes o seu papel no serviço, isto é, o que podem ou não fazer;

- Adicionar experiências. Certos serviços fazem parte da rotina das pessoas, mas nem sempre são considerados prazerosos. Compras em supermercado, por exemplo, costumam ser associadas a filas no caixa. Por isso, algumas redes como Whole Foods Market e St. Marche têm funcionários que demonstram cortes de carne e formas de preparo dos alimentos, além de atendentes treinados para conhecer todos os produtos comercializados e, assim, auxiliar os clientes em suas decisões de compra. Seu negócio presta um serviço rotineiro e essencial? Em quais atividades é possível criar ou adicionar experiências? Assim como na primeira estratégia, os funcionários têm papel-chave na execução de tarefas singulares e dedicadas aos clientes. Por isso, vale a pena pensar se 


\section{MIGRAR DE SERVIÇOS COMUNS PARA SERVIÇOS COMO DESTINO PODE EXIGIR MUDANÇAS EM TERMOS DE LAYOUT, INSTALAÇÕES, SUPRIMENTOS, TREINAMENTO DE PESSOAL, PADRÃO DE ATENDIMENTO E INTERAÇÃO COM O CLIENTE.}

a equipe de atendimento precisa de treinamento ou de mudança de abordagem. Adaptações no layout das instalações também podem ser necessárias;

- Estender a experiência. Há serviços que oferecem experiências, mas por um curto espaço de tempo. Assistir a uma partida de futebol é algo marcante, porém a experiência dura o tempo de uma partida. Por isso, atualmente, estádios de futebol como as arenas do Grêmio e do Corinthians, o Maracanã e o Pacaembu têm museus e exposições internos. Torcedores podem passar horas, antes ou depois do jogo, apreciando camisas autografadas, bustos, troféus e vídeos. Empresas que já oferecem experiências aos seus clientes devem pensar: o que podemos adicionar para aumentar a duração dessa experiência? Novas experiências muitas vezes envolvem serviços diferentes dos já prestados pelas empresas, como é o caso dos museus internos, que possuem instalações, horários de funcionamento e recursos distintos daqueles dos estádios de futebol. Portanto, essa estratégia pode envolver um investimento considerável;

- Criar múltiplas experiências. Em vez de prestar um único serviço, um negócio pode englobar mais de uma experiência e atingir outros mercados além do original. Serviços como os de cabeleireiros e barbeiros "roubam" o tempo de lazer dos clientes. Salões masculinos como o Barbello's Barbearia, que possui uma mesa de sinuca, ou a Barbearia Corleone, que conta com um cardápio de 450 rótulos de cerveja, procuram mudar essa percepção ao transformarem seu negócio em um ponto de encontro para amigos que não se veem há vários anos. Pense: quais são as diferentes necessidades dos seus clientes? Quais serviços ou atividades atendem a essas necessidades e possuem relação com o seu negócio? Seria possível agradar a outros públicos? Essa estratégia pode demandar investimentos em mudanças de layout do estabelecimento e parcerias com outros prestadores de serviço. Há que se considerar a possibilidade de instalar autosserviços, como no caso da mesa de sinuca no Barbello's.

\section{PARA ALINHAR AS OPERAÇÕES ÀS EXPERIÊNCIAS}

As quatro estratégias apresentadas são um ponto de partida para as empresas que desejam transformar seus serviços em um destino capaz de oferecer experiências singulares aos clientes, no entanto vale ressaltar que o sucesso depende de uma implantação operacional adequada, que alinhe os custos aos benefícios da experiência. Pense nas mudanças que a empresa deverá fazer em termos de layout, instalações, suprimentos, treinamento de pessoal, padrão de atendimento e interação com o cliente.

Muitas tentativas de transformar o serviço em destino falham, porque exigem altos investimentos em mudanças em infraestrutura que acabam não se pagando. Por isso, é importante considerar alternativas para transformar o ambiente físico que possam ser flexibilizadas, caso necessário, e que exijam menos aportes para determinado nível de experiência. Integrar as diferentes áreas da empresa, como marketing, recursos humanos e operações, com o objetivo de fornecer determinadas experiências ao cliente, é fundamental para otimizar o uso de recursos e para atingir os objetivos. Consumidores podem participar de fóruns on-line e testes em que experimentam as inovações, para que assim se possam identificar quais emoções e atitudes a experiência desperta.

Independentemente da estratégia que você escolher para transformar o seu serviço comum em um serviço como um destino, lembre-se de que alinhar suas operações vai permitir alcançar a experiência desejada sem comprometer o retorno financeiro.
PARA SABER MAIS:

Robert Johnston e Xiangyu Kong. The customer experience: a road-map for improvement. Managing Service Quality, An International Journal, v.21, n.1, 2011.

doi.org/10.1108/09604521111100225

B. Joseph Pine e James H. Gilmore. The experience economy: work is theatre \& every business a stage, 1999.

Madeleine E. Pullman e Michael A. Gross. Ability of experience design elements to elicit emotions and loyalty behaviors. Decision Sciences, v.35, n.3, 2004. doi.org/10.1111/ j.0011-7315.2004.02611.x

Christopher A. Voss, Aleda V. Roth, Richard B. Chase. Experience, service operations strategy, and services as destinations: foundations and exploratory investigation. Production and Operations Management, v.17, n.3, 2008. doi.org/10.3401/poms.1080.0030

Leonieke G. Zomerdijk e Christopher A. Voss. Service design for experience-centric services. Journal of Service Research, v.13, n.1, 2010. doi.org/10.1177\%2F1094670509351960 Sriram Dasu e Richard. B Chase. The customer service solution: Managing emotions, trust and control to win your customer's business, 2013.

WANDICK LEÃO > Doutorando em Administração de Empresas pela FGV EAESP e professor auxiliar do Insper > wandicklf@insper.edu.br

JULIANA BONOMI SANTOS > PhD em Management Science (Lancaster University Management School) e Professora da FGV EAESP > juliana.bonomi@fgv.br 